\title{
Alvarado Score Still Holds: A Prospective Comparison of Modified Alvarado Score [MAS] and Appendicitis Inflammatory Response Score [AIRS] as a Diagnostic Aid in Acute Appendicitis
}

\author{
Varun Kumar Singh ${ }^{1}$, Bikram Kharga ${ }^{2}$, Kumar Nishant ${ }^{2}$, Phuchungla Bhutia ${ }^{1}$, Barun Kumar Sharma ${ }^{3}$, \\ Neha Pandey 4 .
${ }^{1}$ Assistant Professor, Department of Surgery. ${ }^{2}$ Associate Professor, Department of Surgery. ${ }^{3}$ Associate Professor, Department of Radiodiagnosis. ${ }^{4} \mathrm{MBBS}$ - Undergraduate Student. All authors are from Sikkim Manipal Institute of Medical Sciences, \\ Gangtok, India
}

Address for Correspondence: Varun Kumar Singh, Department of Surgery, Sikkim Manipal Institute of Medical Sciences, $5^{\text {th }}$ Mile, Tadong, Gangtok, Sikkim. India. Mail Id: varunsingh.vks@gmail.com

\begin{abstract}
Introduction: In pre-imaging era, diagnosis of appendicitis was based on clinical assessment. To decrease chances of error and negative appendectomy, Alvarado was first to propose a score in 1885. A number of scores were then put forward including modification of Alvarado score. This study aimed to compare two most commonly used systems, MAS and AIRS. Methods: On admission MAS and AIRS were compared in patients of right iliac fossa pain who subsequently underwent appendectomy. Histopathologic examination was taken as gold standard outcome and MAS and AIRS as tests under evaluation. Results: Study analysed 229 patients with a mean age of 32.69 years and male to female ratio of 1.04 . Female patients were older than male patients [ 35.25 and 30.14 years, respectively; $p=0.017$ ]. Negative appendectomy rate was just under $4 \%$. Sensitivity, specificity, PPV and NPV of MAS were $85 \%, 44.4 \%, 97.4 \%$ and $10.8 \%$ and for AIRS were $81.8 \%$, $11.1 \%, 95.7 \%$ and $2.4 \%$. Sensitivity in children and adolescents was $90 \%$ and $72.5 \%$ for MAS and AIRS, respectively. There was no gender difference between the two. AUC for ROC curve of MAS and AIRS was 0.669 [0.474-0.863] and 0.481 [0.285-0.677] with a significant difference [ $\mathrm{p}=0.0003]$. Conclusion: Both scores are sensitive, underdiagnose patients as low risk, but don't leave any patient with advanced appendicitis. MAS outperforms AIRS for all cases of appendicitis as well as advanced appendicitis. Since both scores classify a large number of patients as low risk, before deciding a surgical intervention, an imaging aid should always be welcome.
\end{abstract}

Key words- AIRS, Alvarado, Appendicitis, Appendectomy, MAS

\section{Introduction}

The diagnosis of acute appendicitis, the most common surgical abdominal emergency [i] has been a clinical quandary and continues to be so. Though the rate of incorrect diagnoses has come down with the advent of high end diagnostic modalities like ultrasonography and computed tomography, the surprises continue to pop up even now [ii].

Manuscript Received: 24 $4^{\text {th }}$ August 2016

Reviewed: $6^{\text {th }}$ September 2016

Author Corrected: $18^{\text {th }}$ September 2016

Accepted for Publication: 30 $0^{\text {th }}$ September 2016
It is not uncommon to have a decision making dilemma, whether or not to explore a patient even after imaging work up, when the literature still documents a negative appendectomy rate somewhere between 15-34\% [ii, iv]. And therefore, finally it rests on clinical acumen. Various scores [which include clinical, biochemical, their combinations and emphasis on repeated examinations] have been proposed and compared to each other over and again but to no avail [ [ ${ }^{\mathrm{v}}$ vi vii viii]. Most common scores in use are original Alvarado score [OAS] and its modification [MAS] and Appendicitis Inflammatory 
Response Score [AIRS]. This study has tried to examine the status of MAS and AIRS in the ethnic population of Sikkim, a north east state of India.

\section{Patients and Methods}

A prospective observational analytic study was planned to evaluate and compare the on admission Modified Alvarado Score [MAS] and Appendicitis Inflammatory Response Score [AIRS] in patients of right iliac fossa pain, in whom an appendicular pathology was suspected.

The intra-operative findings and post-operative histopathology of the specimen were then compared to MAS and AIRS.

The study was conducted in Sikkim Manipal Institute of Medical Sciences in Gangtok, the capital town of Sikkim, one of the north east states of India and lasted over a duration of 2 years from April 2013 to March 2015. Patients of all age groups were included provided they underwent appendectomy in the institution. There were no major exclusions except a mismatch in recording of data. Histopathological examination was taken as the gold standard outcome and MAS and AIRS as tests under evaluation.

The recording of data [of MAS and AIRS] was designed in such a way so that each of the scores were recorded by two surgeons independently [Table 1]. Thus there were 4 surgeons, two of them recorded MAS and two recorded AIRS.

Any mismatch in data recorded by the two surgeons was a criteria kept for exclusion. Data was tabulated and analysed using IBM $^{\odot}$ SPSS $^{\odot} 20.0$ and Microsoft $^{\odot}$ Excel $^{\odot}$ 2013.

\section{Results}

Over a study duration of 2 years, 267 patients underwent surgery for an indication of appendicular pathology in the institute. After carefully scrutinizing recorded data, 38 patients who had a mismatch in entries recorded by the two surgeons independently, were excluded.

Thus, data of 229 patients was analysed after the end of the study. Of these 229 patients, 226 patients underwent appendectomy and 3 patients had the intra-operative diagnosis of perforated Meckel's diverticulum and were regarded as negative appendectomies while analysing the data.

Male patients marginally outnumbered female patients by a male to female ratio of 1.04 . The mean age of the study population was 32.69 years. Most of the patients were young as half of the patients [50.3\%] were in $3^{\text {rd }}$ and $4^{\text {th }}$ decade of life. Children and adolescents formed $23.2 \%$ of total cases.

The distribution of male and female patients across age groups was a significant observation as the sex ratio reversed from that in favour of males to that of females as the age advanced. Consequently female patients had a higher mean age [35.35 years] compared to male counterparts [30.14 years] [ $\mathrm{df}=1, \mathrm{~F}=5.819, \mathrm{p}=0.017]$ [Table 2].

Out of 226 histopathologic examinations, 185 patients had a diagnosis of acute appendicitis and 20 patients had acute on chronic appendicitis. Number of patients with chronic appendicitis was 10 and 5 patients had acute eosinophilic appendicitis. There were 6 patients [2.6\%] who had usual histology of normal appendix. Three patients had perforation of Meckel's diverticulum. Thus there were 9 [3.9\%] negative appendectomies [Table 3].

MAS predicted high likelihood of appendicitis in 94 patients [41\%] while the score remained indeterminate or borderline in 98 patients [42.8\%]. There were 37 patients [16.2\%] in whom MAS was 4 or less thus almost excluding the possibility of appendicitis.

Comparing the data with histopathology of the appendix specimen, MAS could truly predict the least possibility of appendicitis in 4 out of 6 patients while in remaining 2 patients the score was borderline. However, in those 94 patients in whom MAS predicted high likelihood of appendicitis, final histology was appendicitis [Table 3]. 
Compared to MAS [41\%], AIRS could definitely predict AIRS in 34 patients [14.8\%]. The score was borderline in almost two thirds of patients [67.2\%]. However, the number of patients in whom AIRS predicted least likelihood of appendicitis was comparable to MAS [41 (17.9\%) and 37 (16.2\%) for MAS and AIRS, respectively].

Out of 6 patients with final histology of normal appendix, AIRS could predict least possibility of appendicitis in 1 patient, and 5 patients had a preoperative diagnosis of borderline appendicitis. In those 34 patients in whom AIRS predicted definitive appendicitis, no patient was found to have a negative report of appendicitis [Table 3].

Mean MAS and AIRS of the patients was 6.20 [out of 9] and 6.24 [out of 12], respectively, both in the borderline range. The value of both MAS and AIRS was lower for male patients [6.02 and 6.19, respectively], compared to female patients [6.38 and 6.29 respectively]. However, the difference of mean MAS and mean AIRS between the two genders was not significant $[p=0.076$ and 0.699 , respectively] concluding both the score predict the probability of appendicitis in a similar way between the two genders.

When the MAS and AIRS were compared independently among the various age groups, we found the scores to be more predictable in middle age group patients compared to those in immediate younger and older age groups. However, predictability again increased in extremes of ages [p<0.001] [Table 4, Figure 1].

Mean percentage scores of MAS and AIRS were 68.85 and 51.96 , respectively $[\mathrm{df}=228, \mathrm{t}=15.13$, $\mathrm{p}<0.001]$. For the same patient, MAS could achieve a higher score compared to AIRS and therefore predicted the possibility of appendicitis in a more definite way.

Table-1: Comparison between MAS and AIRS

\begin{tabular}{|c|c|c|c|}
\hline \multicolumn{2}{|c|}{ Parameters } & MAS & AIRS \\
\hline \multirow[t]{3}{*}{ Symptoms } & Migratory RIF pain & 1 & 1 \\
\hline & Anorexia & 1 & -- \\
\hline & Nausea/ vomiting & 1 & 1 \\
\hline \multirow[t]{3}{*}{ Signs } & Tenderness RIF & 2 & -- \\
\hline & Rebound tenderness in RIF & 1 & $\begin{array}{c}1 \text { [Mild }] \\
2[\text { Moderate }] \\
3[\text { Severe }]\end{array}$ \\
\hline & Elevated temperature & 1 & 1 \\
\hline \multirow[t]{3}{*}{ Investigations } & Leucocytosis & $2\left[\geq 10 \times 10^{3} /\right.$ cumm $]$ & $\begin{array}{c}1\left[10 \times 10^{3}-14.9 \times 10^{3} / \mathrm{cumm}\right] \\
2\left[\geq 15 \times 10^{3} / \text { cumm }\right]\end{array}$ \\
\hline & Polymorphs & -- & $\begin{array}{c}1[70-84 \%] \\
2[\geq 85 \%]\end{array}$ \\
\hline & CRP & -- & $\begin{array}{c}1[1-4.9 \mathrm{mg} / \mathrm{l}] \\
2[\geq 5 \mathrm{mg} / \mathrm{l}]\end{array}$ \\
\hline & Total & $0-9$ & $0-12$ \\
\hline \multicolumn{2}{|c|}{ Interpretation } & $\begin{array}{c}\text { 0-4 Low probability } \\
\text { 5-7 Borderline/ Equivocal } \\
\text { 8-9 High probability }\end{array}$ & $\begin{array}{c}\text { 0-4 Low probability } \\
\text { 5-8 Borderline/ Equivocal } \\
\text { 9-12 High probability }\end{array}$ \\
\hline
\end{tabular}


Table-2: Patients' distribution across their age and gender along with mean MAS and AIRS

\begin{tabular}{|c|c|c|c|c|c|c|c|c|c|}
\hline \multirow{2}{*}{$\begin{array}{c}\text { Age } \\
\text { Group }\end{array}$} & \multicolumn{3}{|c|}{ N } & \multicolumn{3}{c|}{ Mean MAS } & \multicolumn{3}{c|}{ Mean AIRS } \\
\cline { 2 - 10 } & Male & Female & Total & Male & Female & Overall & Male & Female & Overall \\
\hline $0-10$ & 7 & 6 & 13 & 7.43 & 7.67 & 7.54 & 7.00 & 8.00 & 7.46 \\
\hline $11-20$ & 24 & 16 & 40 & 6.29 & 6.25 & 6.28 & 6.50 & 5.50 & 6.10 \\
\hline $21-30$ & 41 & 26 & 67 & 5.63 & 5.62 & 5.63 & 5.63 & 5.38 & 5.54 \\
\hline $31-40$ & 22 & 26 & 48 & 5.64 & 6.69 & 6.21 & 6.18 & 7.04 & 6.65 \\
\hline $41-50$ & 12 & 19 & 31 & 7.00 & 6.89 & 6.94 & 6.50 & 6.79 & 6.68 \\
\hline $51-60$ & 6 & 9 & 15 & 5.17 & 6.33 & 5.87 & 7.83 & 7.44 & 7.60 \\
\hline $61-70$ & 3 & 5 & 8 & 5.67 & 5.80 & 5.75 & 5.00 & 5.00 & 5.00 \\
\hline $71-80$ & 1 & 3 & 4 & 6.00 & 6.00 & 6.00 & 4.00 & 4.00 & 4.00 \\
\hline $81-90$ & 1 & 1 & 2 & 8.00 & 6.00 & 7.00 & 8.00 & 4.00 & 6.00 \\
\hline$\geq 91$ & 0 & 1 & 1 & -- & 8.00 & 8.00 & -- & 8.00 & 8.00 \\
\hline Total & 117 & 112 & 229 & 6.02 & 6.38 & 6.20 & 6.19 & 6.29 & 6.24 \\
\hline
\end{tabular}

Table-3: Final Histopathology and MAS and AIRS stratification across diagnosis

\begin{tabular}{|c|c|c|c|c|c|c|c|}
\hline \multirow{2}{*}{$\begin{array}{l}\text { Scoring } \\
\text { System }\end{array}$} & \multirow{2}{*}{$\begin{array}{c}\text { Score and } \\
\text { Probability }\end{array}$} & \multicolumn{4}{|c|}{ Appendicitis } & \multirow{2}{*}{$\begin{array}{c}\text { Normal } \\
\text { Histology }\end{array}$} & \multirow[t]{2}{*}{ Total } \\
\hline & & Acute & $\begin{array}{c}\text { Acute on } \\
\text { chronic }\end{array}$ & Chronic & $\begin{array}{c}\text { Acute } \\
\text { Eosinophilic }\end{array}$ & & \\
\hline \multicolumn{2}{|r|}{$\mathbf{N}$} & 185 & 20 & 10 & 5 & $6+3 *$ & 229 \\
\hline \multirow[t]{3}{*}{ MAS } & 0-4 Low & 24 & 7 & 1 & 1 & $4+1 *$ & 38 \\
\hline & 5-7 Borderline & 84 & 2 & 6 & 3 & $2+2 *$ & 99 \\
\hline & 8-9 High & 77 & 11 & 3 & 1 & 0 & 92 \\
\hline \multirow[t]{3}{*}{ AIRS } & 0-4 Low & 39 & 0 & 1 & 0 & 1 & 41 \\
\hline & 5-8 Borderline & 115 & 20 & 9 & 4 & $5+1 *$ & 154 \\
\hline & 9-12 High & 31 & 0 & 0 & 1 & $0+2 *$ & 34 \\
\hline
\end{tabular}

Table-4: Binary Classifiers at cut-off 5 for MAS and AIRS in male, female and paediatric patients*

\begin{tabular}{|c|c|c|c|c|c|c|c|}
\hline $\begin{array}{l}\text { Scoring } \\
\text { System }\end{array}$ & Gender & Sensitivity & Specificity & PPV & NPV & LR+ & LR- \\
\hline \multirow[t]{3}{*}{ MAS } & Male & 82.9 & 50 & 96.8 & 13.6 & 1.66 & 0.34 \\
\hline & Female & 87.2 & 33.3 & 97.9 & 6.7 & 1.31 & 0.38 \\
\hline & Children* + & 90 & -- & 97.3 & -- & -- & -- \\
\hline \multirow[t]{3}{*}{ AIRS } & Male† & 84.7 & -- & 94 & -- & -- & -- \\
\hline & Female & 78.9 & 33.3 & 97.7 & 4.2 & 1.18 & 0.63 \\
\hline & Children*t & 72.5 & -- & 96.7 & -- & 0.7 & -- \\
\hline
\end{tabular}


Table-5: Binary Classifiers at different cut-offs for MAS and AIRS

\begin{tabular}{|c|c|c|c|c|c|c|c|}
\hline $\begin{array}{c}\text { Cut-off } \\
\text { Value }\end{array}$ & $\begin{array}{c}\text { Scoring } \\
\text { System }\end{array}$ & Sensitivity & Specificity & PPV & NPV & LR+ & LR- \\
\hline \multirow{2}{*}{5} & MAS & $\mathbf{8 5 . 0}$ & $\mathbf{4 4 . 4}$ & $\mathbf{9 7 . 4}$ & $\mathbf{1 0 . 8}$ & $\mathbf{1 . 5}$ & $\mathbf{0 . 3}$ \\
\cline { 2 - 8 } & AIRS & $\mathbf{8 1 . 8}$ & $\mathbf{1 1 . 1}$ & $\mathbf{9 5 . 7}$ & $\mathbf{2 . 4}$ & $\mathbf{0 . 9}$ & $\mathbf{1 . 6}$ \\
\hline \multirow{2}{*}{6} & MAS & 62.7 & 66.7 & 97.9 & 6.8 & 1.9 & 0.6 \\
\cline { 2 - 8 } & AIRS & 58.6 & 44.4 & 96.3 & 4.2 & 1.1 & 0.9 \\
\hline 7 & MAS & 41.8 & 77.8 & 97.9 & 5.2 & 1.9 & 0.7 \\
\cline { 2 - 8 } & AIRS & 45.9 & 66.7 & 97.1 & 4.8 & 1.4 & 0.8 \\
\hline 8 & MAS & $\mathbf{2 3 . 6}$ & $\mathbf{8 8 . 9}$ & $\mathbf{9 8 . 1}$ & $\mathbf{4 . 5}$ & $\mathbf{2 . 1}$ & $\mathbf{0 . 9}$ \\
\cline { 2 - 8 } & AIRS & 30.0 & 66.7 & 95.7 & 3.8 & 0.9 & 1.0 \\
\hline 9 & MAS & 10.5 & 100 & 100 & 4.4 & -- & 0.9 \\
\cline { 2 - 8 } & AIRS & $\mathbf{1 4 . 5}$ & $\mathbf{7 7 . 8}$ & $\mathbf{9 4 . 1}$ & $\mathbf{3 . 6}$ & $\mathbf{0 . 7}$ & $\mathbf{1 . 1}$ \\
\hline
\end{tabular}

Bold fonts indicate the lower and higher cut-offs for MAS and AIRS, respectively. The final comparison between MAS and AIRS has been done at cut-off 5 [for both] for lower threshold and at cut-off 8 for MAS and 9 for AIRS.

Figures

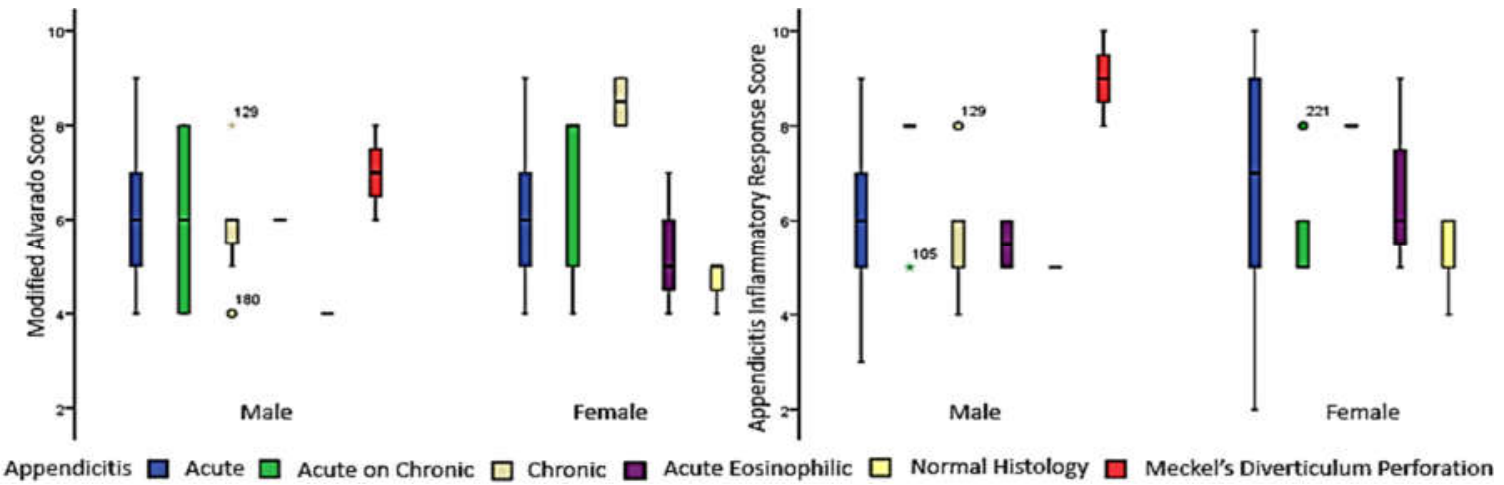

Figure 1: Box plots showing the central tendency and distribution of Modified

Alvarado and Appendicitis Response Score among two genders across histology.

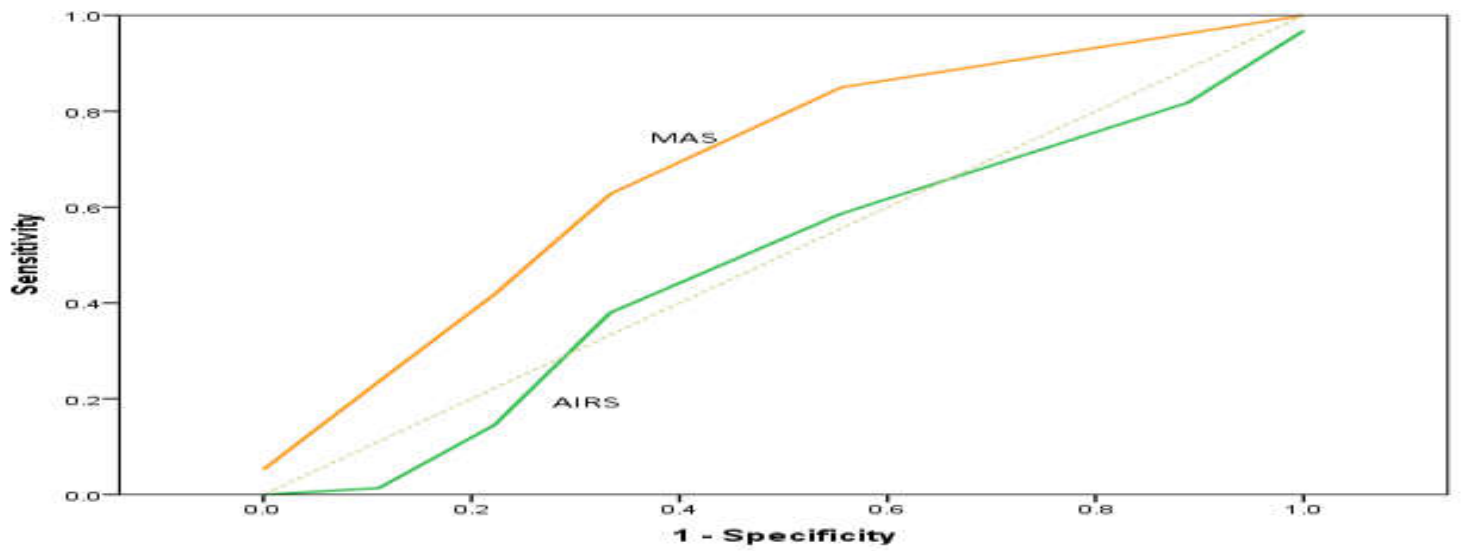

Figure 2: ROC curves for MAS and AIRS. The area under curve [AUC] is larger for MAS than that for AIRS [p=0.0003]. 
At the borderline cut-off value of 5, both MAS and AIRS were highly sensitive [ $85 \%$ and $81.8 \%$, respectively], however, MAS was much more specific compared to AIRS [44.4\% and $11.1 \%$, respectively]. As the cut-off values are increased, sensitivity of both the scoring systems decline sharply. At the defined cut-off for high probability of appendicitis for both the systems [ 8 for MAS and 9 for AIRS], MAS remained more sensitive and specific compared to AIRS, though the sensitivity was too low compared to cut-off of 5. Positive predictive value of MAS improved while that of AIRS declined on increasing the value of cut-off, even though the value remained above $94 \%$ of both the scores at all cut-offs [Table 5]. The area under curve [AUC] for receiver operating characteristic [ROC] curves for MAS was 0.689 [95\% CI: 0.506-0.872] and for AIRS was 0.481 [0.285-0.677] with statistically significant difference [ $\mathrm{p}=0.0003$ ]. The curve of AIRS is dipped twice below reference line indicating the utility of AIRS as a diagnostic tool in appendicitis is very poor [Figure 2].

\section{Discussion}

Taking a call for operative intervention in non-traumatic acute abdomen is not easy especially when there is limited access to imaging in an emergency set up. The bulk of these cases are acute appendicitis. Over the study duration of 2 years, 3,285 patients of all age groups were admitted with complaints of either right lower abdomen pain or poorly localized/ diffuse lower abdomen pain in surgery ward. Of these, 267 patients underwent appendectomy constituting $8.13 \%$ of the total population of patients presenting with some symptoms suspicious of appendicitis.

Pouget-Baudry reviewed the role of OAS in management of right lower quadrant pain and found a score of less than 4 was associated with absence of appendicitis while more than 6 was significantly associated with acute appendicitis [ix $]$. In a retrospective study [ $\mathrm{n}=155]$, done in our institute in 2010, Dey et al [including the authors of this study] concluded OAS could be an easy, simple, effective and cheap alternative to imaging modalities which are not readily available in developed countries.

Overall sensitivity and specificity were $94.2 \%$ and $70 \%$ with a PPV of $86.9 \%$ and NPV of $69.8 \%$ [ ${ }^{\mathrm{x}}$ ]. Denizbasi found the sensitivity and specificity of OAS to be $95.4 \%$ and $45 \%$, respectively $\left.{ }^{[\mathrm{x}}\right]$. We used MAS rather than OAS in our study and its sensitivity and specificity were less $[85 \%, 44.4 \%$, respectively]. Minimum MAS score in our study was 4 and no patient had a score less than that. Ozkan et al in his retrospective study found sensitivity, specificity, PPV and NPV of OAS were 54\%, 73.3\%, $88.2 \%$ and $29.7 \%$, respectively with a significant difference between the two genders [sensitivity $=64.3 \%$, $28.6 \%$; specificity $57.1 \%, 75 \%$; PPV $=90 \%, 66.7 \%$ and $\mathrm{NPV}=21.1 \%, 37.5 \%$, respectively for men and women] [xii]. Denizbasi also found significant gender difference in $\mathrm{PPV}[p=0.045]$ and NPV $[p=0.02][11]$.
However, we didn't find any difference between the mean percentage scores of two genders $[\mathrm{p}=0.176$ and 0.117 , respectively for MAS and AIRS].

In Ebell's systematic review of 28 prospective studies, $\mathrm{LR}+$ for OAS in adults were $0.03,0.42$ and 3.4 for cutoffs $<4,4-6$ and $>6$, respectively and $0.01,0.98$ and 6.7 for cut-offs $<5,5-8$ and $>8$, respectively. Similarly, the values for children were $0.02,0.27,4.2$ [for $<4,4-6,>6$ ] and $0.04,1.2,8.5$ [for $<5,5-8,>8$ ]. Overall LR+ in our study was 1.5 for a cut-off for 5, 1.9 for cut-off of 6 and 7 and 2.1 for a cut-off 8 in case of MAS. In case of AIRS the LR+ was highest [1.4] for cut-off of 7 [xiii]. Golden et al [ $\mathrm{n}=287]$ found OAS had a positive likelihood ratio [LR+] of 2.2 [95\% CI: 1.7-3] and negative likelihood ratio [LR-] of 0.6 [0.4-0.7]. Similar values for MAS were 2.4 [1.6-3.4] and 0.7 [0.6-0.8] [ $\left.{ }^{\mathrm{xiv}}\right]$. The LR+ in present study was 1.5 and 0.9 for MAS and AIRS, respectively while the LR- was 0.3 and 1.6.

In Ohle's systematic review of 42 studies related to the OAS in predicting appendicitis, he found the OAS to be a useful diagnostic tool in ruling out acute appendicitis at a cut-off of 5 for all patient groups. He also concluded that the score works well in male patients but is inconsistent in children and tends to over predict appendicitis in female patients. In our study, MAS was better than AIRS in ruling out appendicitis as MAS predicted 5 [55.55\%] patients as low risk out of 9 patients with final negative histology [including three patients with intra-operative diagnosis of Meckel's diverticulum] but AIRS could predict only 1 [11.11\%] patient as low risk. In children MAS was $90 \%$ sensitive compared to overall sensitivity of $85 \%$ but the sensitivity of AIRS was lower compared to overall sensitivity $[72.5 \%$ and $81.8 \%$, respectively]. However, both the MAS and AIRS predicted the only child with negative histology as low risk $\left[{ }^{\mathrm{x}}\right]$. Bundy, in 
his meta-analysis of 42 level 3 articles, concluded OAS and MAS worked best in older age groups. Chances of appendicitis rose to 4 fold if the score was 7 or more [LR=4.0 for OAS and 3.6 for MAS] and dipped to $4 / 5^{\text {th }}$ if it was less than 7 [LR=0.20 for OAS and 0.30 for MAS]. In our study MAS had an overall LR (+) of 1.9 for a cutoff of 7 and 2.1 for a cut-off of 8 [ ${ }^{\text {xvi }}$.

Ohmann did a prospective interventional [before and after trial] study [ $n=1484]$ where he compared a group of standard diagnostic workup without any additional diagnostic support with a group of patients undergoing additional diagnostic support with a score and concluded that the integration of a clinical score in the diagnostic process cannot be recommended as a standard diagnostic tool for decision making in acute appendicitis [ $\left.{ }^{\mathrm{x} v i i}\right]$.

Scott et al calculated AIRS during a 50 week prospective study [ $n=464]$ and found $63.3 \%$ patients had low risk, however $6.2 \%$ of them had appendicitis. In contrast we had $17.9 \%$ patients classified as low risk through AIRS but almost all of them except one had appendicitis on final histology. Sensitivity and specificity were 90\% [cut-off 5] and $98 \%$ [cut-off 9], respective values in our study were $81.8 \%$ and $77.8 \%$ [ $\left.{ }^{\mathrm{x} v i i}\right]$.

Chong et al compared OAS and RIPASA score derived from 192 patients with right iliac fossa pains and found OAS to be less sensitive for Asian population. The sensitivity of OAS [cut-off 7] and RIPASA score [cut-off 7.5] were $68.3 \%$ and $98 \%$, respectively, while at a similar cut-off of 7 , the MAS was just $41.8 \%$ sensitive and AIRS was $45.9 \%$. However, the comparison was between a 10 point score [MAS] and 17.5 point score [RIPASA] at almost a similar cut-off [7 and 7.5, respectively] and at a cut-off of 5, MAS, though still lagging, is not far behind RIPASA score in our study [ $\left.{ }^{\mathrm{xix}}\right]$.

Kollar et al compared AIRS, OAS and initial impression of a senior surgeon and found all methods stratified similar proportions $[\sim 40 \%]$ of patients to low risk $[p=0.233]$ with a false negative rate $[\mathrm{FNR}]$ of $<8 \%$. While MAS and AIRS in our study could stratify $16.15 \%$ and $17.9 \%$ patients to low risk [ $p=0.309$ ] with an FNR of $15 \%$ and $18.2 \%$, respectively. AIRS assigned a much smaller proportion to high risk patients compared to OAS [14 and $45 \%$, respectively] in his study. Similarly AIRS identified $14.8 \%$ and MAS $41 \%$ patients as high risk $[p<0.001]$. In contrast to Kollar's finding of higher specificity and PPV of AIRS [97\% and $88 \%$, respectively] compared to OAS [76\% and 65\%, respectively], our AIRS was less specific and had a lower PPV [77.8\% and 94.1\%, respectively] compared to MAS [88.9\% vs $98.1 \%$ ] [ $\left.{ }^{\mathrm{xx}}\right]$.

Sammalkorpi et al developed a new adult appendicitis score and prospectively compared it to OAS and AIRS. OAS outperformed the rest in terms of sensitivity, but the specificity and LR were better in the new score as well as AIRS. The AUC of new score was 0.882 [0.858-0.906] and of OAS and AIRS was 0.790 [0.758-0.823] and 0.810

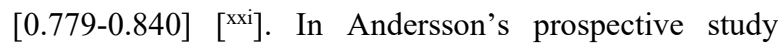
[n=545], AIRS outperformed OAS. AUC for AIRS was 0.93 for all cases of appendicitis compared to 0.88 for OAS $[p=0.0007]$, the values for advanced appendicitis were 0.97 and 0.92 , respectively $[p=0.0027$ [ [xii].

Golden found AUC for MAS was 0.7 and was not significantly different from that in OAS [0.72], physician determined likelihood [0.72] or RIPASA score [0.67] [14]. deCastro plotted ROC curves in a prospective study [n=941, 346 had appendicular pathology] and AUC was greater for AIRS [0.96 for AIRS, 0.82 for OAS, $\mathrm{p}<0.05$ ]

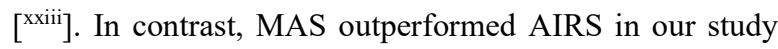
with values of AUC for MAC was 0.669 and for AIRS was $0.438[\mathrm{p}=0.0003]$.

\section{Conclusion}

Both MAS and AIRS are quite sensitive at lower threshold but underdiagnose a fair number of patients as low risk, even when they have appendicitis but don't leave any patient with advanced appendicitis even at a higher threshold. However, MAS outperforms AIRS in most of the parameters for both all cases of appendicitis as well as advanced appendicitis. Both the scores are more predictable in middle age and in extremes of age and can be used in children and old age patients with similar predictability. Since both scores classify a large number of patients as low risk, before deciding a surgical intervention, an imaging aid should always be welcome.

Limitation- We took final histopathology as the gold standard for diagnosis of appendicitis. So those patients who couldn't undergo appendectomy but probably had appendicitis, were excluded from the study thus decreasing the false negatives. 
They were those patients who were classified as low risk by any of the two scores and a subsequent imaging failed to show an appendicular pathology.

Acknowledgement- The authors acknowledge the help from department of Pathology, Sikkim Manipal Institute of Medical Sciences.

\section{Conflict of Interests-None}

\section{References}

1. Gwynn LK. The diagnosis of acute appendicitis: clinical assessment versus computed tomography evaluation. J Emerg Med. 2001;21(2):119-123. DOI: 10.1016/S0736-4679(01)00353-5.

2. Shogilev DJ, Duss N, Odom SR, et al. Diagnosing Appendicitis: Evidence based review of the diagnostic approach in 2014. West J Emerg Med. 2014;15(7):859871. DOI: 10.5811/westjem.2014.9.21568.

3. Bergeron E. Clinical judgment remains of great value in the diagnosis of acute appendicitis. Can J Surg. 2006;49(2):96-100.

4. Flum DR, Morris A, Koepsell T, et al. Has misdiagnosis of appendicitis decreased over time? A population-based analysis. JAMA. 2001;286(14):17481753. DOI: 10.1001/jama.286.14.1748.

5. Humes DJ, Simpson J. Clinical presentation of acute appendicitis: Clinical Signs-Laboratory findingsClinical scores, Alvarado score and derivate scores. In: Keyzer C, Gevenois A (Editors). Imaging of acute appendicitis in adults and children, Medical Radiology. Diagnostic Imaging. Springer-Verlag Berlin Heidelberg 2011. DOI: 10.1007/174_2011_211.

6. Andersson RE. Meta-analysis of the clinical and laboratory diagnosis of appendicitis. $\mathrm{Br} \quad J \quad$ Surg. 2004;91(1):28-37. DOI: 10.1002/bjs.4464.

7. Andersson RE, Hugander A, Ravn H, et al. Repeated clinical and laboratory examinations in patients with an equivocal diagnosis of appendicitis. World J Surg. 2000;24:479. DOI: 10.1007/s002689910076.
8. Anielski R, Kusnierz-Cabal B, Szafraniee K. An evaluation of the utility of additional tests in the preoperative diagnostics of acute appendicitis. Langenbecks Arch Surg. 2010;395:1061-1068. DOI: 10.1007/s00423-009-0565-x.

9. Pouget-Baudry Y, Mucci S, Eyssartier E, et al. The use of the Alvarado score in the management of right lower quadrant abdominal pain in the adult. J Visc Surg. 2010; 147(2):40-44. DOI: 10.1016/j. jviscsurg. 2010.05.002.

10. Dey S, Mohanta P, Baruah AK, et al. Alvarado scoring in acute appendicitis-a clinicopathological correlation. Indian J Surg. 2010;72(4):290-293. DOI: 10.1007/s12262-010-0190-5.

11. Denizbasi A, Unluer EE. The role of the emergency medicine resident using the Alvarado score in the diagnosis of acute appendicitis compared with the general surgery resident. Eur J Emerg Med. 2003;10(4):296-301.

12. Ozkan S, Duman A, Durukan P, et al. The accuracy rate of Alvarado score, ultrasonography, and computerized tomography scan in the diagnosis of acute appendicitis in our centre. Niger $J$ Clin Pract. 2014;17:413 - 418. DOI: 10. 4103 /1119-3077. 134001.

13. Ebell HE, Shinholser J. What are the most clinically useful cutoffs for the Alvarado and Pediatric Appendicitis Scores? A systematic review. Ann Emerg Med. 2014;64(4):365-372. DOI: 10.1016/j.annemergmed. 2014. 02.025 .

14. Golden SK, Harringa JB, Pickhardt PJ, et al. Prospective evaluation of the ability of clinical scoring system and physician determined likelihood of appendicitis to obviate the need for CT. Emerg Med $J$. 2016;33:458-464. DOI: 10.1136/emermed-2015-205301.

15. Ohle R, O'Reilly F, O'Brien KK, et al. The Alvarado score for predicting acute appendicitis: a systematic review. BMC Medicine. 2011;9:139. DOI: 10.1186/17417015-9-139.

16. Bundy DG, Byerley JS, Liles EA, et al. Does this child have appendicitis? JAMA. 2007;298(4):438-451. DOI: $10.1001 /$ jama.298.4.438. 
17. Ohmann C, Franke C, Yang Q, et al. Clinical benefit of a diagnostic score for appendicitis. Results of a prospective interventional study. Arch Surg. 1999;134(9):993-996.

18. Scott AJ, Mason SE, Arunakirinathan M et al. Risk stratification by the Appendicitis Inflammatory Response score to guide decision making in patients with suspected appendicitis. $B r \quad J$ Surg. 2015;102(5):563-572. DOI: 10.1002/bjs. 9773 .

19. Chong CF, Thien A, Mackle AJA, et al. Comparison of RIPASA and Alvarado scores for the diagnosis of acute appendicitis. Singapore Med J. 2011;52(5):340-345.

20. Kollar D, McCartan DP, Bourke M, et al. Predicting acute appendicitis? A comparison of the Alvarado score, the Appendicitis Inflammatory Response score and clinical assessment. World J Surg. 2015;39(1):104-109. DOI: 10.1007/s00268-014-2794-6.

21. Sammalkorpi HE, Mentula P, Leppaniemi A. A new adult appendicitis score improves diagnostic accuracy of acute appendicitis - a prospective study. BMC Gastroenterology. 2014;14:114. DOI: 10.1186/1471230X-14-114.

22. Andersson M, Andersson RE. The Appendicitis Inflammatory Response Score: A Tool for the Diagnosis of Acute Appendicitis that Outperforms the Alvarado Score. World J Surg. 2008;32(8):1843-1849. DOI: 10.1007/s00268-008-9649-y.

23. deCastro SMM, Unlu C, Steller EP, et al. Evaluation of the Appendicitis Inflammatory Response Score for patients with acute appendicitis. World $J$ Surg. 2012;36:1540-1545. DOI: 10.1007/s00268-012-1521-4.

\section{How to cite this article?}

Varun Kumar Singh, Bikram Kharga, Kumar Nishant, Phuchungla Bhutia, Barun Kumar Sharma, Neha Pandey.Alvarado Score Still Holds: A Prospective Comparison of Modified Alvarado Score [MAS] and Appendicitis Inflammatory Response Score [AIRS] as a Diagnostic Aid in Acute Appendicitis. Int J surg Orthopedics 2016;2(3):21-29.doi: 10.17511/ijoso.2016.i03.01 